Revista Iberoamericana, Vol. LXXVIII, Núms. 238-239, Enero-Junio 2012, 311-328

\title{
LA LÍNEA DE SOMBRA: LITERATURA LATINOAMERICANA Y CIENCIA- FICCIÓN EN TRES NOVELAS CONTEMPORÁNEAS
}

\author{
POR \\ Ezequiel De Rosso \\ Universidad Nacional de Buenos Aires
}

\section{UNA AUSENCIA}

Tal vez uno de los rasgos más curiosos de la literatura latinoamericana que comienza a publicarse durante la década de los noventa (momento señalado por diversos observadores como el inicio de un nuevo momento en las letras del continente) es la ausencia casi completa de textos que puedan inscribirse en el género de la ciencia-ficción. ${ }^{1} \mathrm{Si}$, por ejemplo, se recorren las antologías que a lo largo de la década han producido este efecto de "literatura continental" se verá que, por una parte, casi no existen textos que puedan relacionarse con la ciencia-ficción y, por otra, que las estrategias del policial, el relato fantástico y la novela histórica son frecuentemente utilizados en la construcción de los textos. ${ }^{2}$ Lo mismo podría pensarse en general de la producción de estos escritores durante las décadas del noventa y de dos mil: son muy pocos aquellos textos que, aun sin pertenecer estrictamente al género (no se publican en colecciones especializadas ni en revistas dedicadas al género), pueden relacionarse con sus procedimientos constructivos.

El hecho es curioso por dos motivos. El primero es que estos escritores no parecen preocupados por aquello que otros momentos de la historia literaria se llamaba "alta cultura”. Antes bien, escritores como el ecuatoriano Leonardo Valencia (1969) o el peruano Jaime Bayly (1965), parecen particularmente sensibles a los productos de la

1 Ese efecto de "sincronía" ha recibido diversos nombres en diversos momentos y lugares: "generación de los enterradores", "McOndo", "literatura del crack", "literatura pos-pos-moderna", etc. La década del noventa es el momento en que pareciera volver a hacerse visible el concepto de literatura "latinoamericana", tanto en escritores como en los lectores y en los dispositivos culturales que regulan su relación. Al respecto pueden consultarse Fornet (9-17) y De Rosso (3-7).

2 Nos referimos a las antologías preparadas por Fuguet y Gómez; Ortega, Becerra, Fuguet y Paz Soldán. Se trata de libros que atienden a diversas demandas y por eso es particularmente relevante el hecho de que en estos cuatro libros sólo existe un relato que puede inscribirse dentro del género: “1969, año cero", de Naief Yehya (1963), incluido en la antología compilada por Ortega. 
cultura de masas. ${ }^{3}$ En este sentido, el impacto que la poética del género policial ha tenido en la literatura contemporánea habla a las claras del interés por procedimientos de los géneros llamados “menores”. ${ }^{4}$ Por otra parte, es evidente que este grupo de escritores es consciente de los intertextos que sus obras tienen con la ciencia-ficción: discusiones ficcionales sobre la historia del género, referencias a sus textos canónicos y ensayos sobre la obra de diversos autores son algunas de las formas en las que estos escritores dan cuenta de su relación con la ciencia-ficción. ${ }^{5}$

Así es que la literatura contemporánea (ésa a la que se dedican tesis y monografías, la que se publica en colecciones “generales”) se apropia de las estrategias de los géneros “menores”, lee y comenta ciencia-ficción, pero no parece encontrar en las formas más características del género herramientas para construir ficciones. ${ }^{6}$ Esa ausencia no se debe entonces a que los escritores latinoamericanos desprecien la escritura "popular” (si fuera así no escribirían novelas policiales) ni a que carezcan de tradición genérica (lo que nunca fue un obstáculo para los escritores de género en el Continente) ni de que falten estímulos para la creación de ficciones científicas en la escena contemporánea (nunca como a partir de los noventa fue evidente para el lector latinoamericano el impacto de la tecnología en la vida cotidiana). ${ }^{7}$

Por el contrario, los escritores latinoamericanos surgidos en la década de los noventa no escriben ciencia-ficción porque la dinámica de su escritura bloquea esa posibilidad.

3 Para una introducción a la relación entre cultura de masas y literatura contemporánea ver Amar Sánchez.

4 Para una descripción del impacto del género policial en la literatura contemporánea, ver De Rosso 10113.

5 Ejemplos notables de estos usos pueden encontrarse en la última novela de Rodrigo Fresán (1963), El fondo del cielo (sobre un escritor de ciencia-ficción), en El arma en el hombre, de Horacio Castellanos Moya (1957), cuyo protagonista se llama Robocop. Por su parte, diversos artículos y libros de Pablo De Santis (como "Lo audaz de Avatar es plantear el paraíso”), de Naief Yehya (como El cuerpo transformado), o de Jorge Volpi (como “Réquiem por la novela”), entre otros autores, tienen como referente temas, autores e incluso estrategias centrales para la historia del género. Por lo demás, podría agregarse un tercer motivo para la sorpresa: la década del noventa vio, en casi todo el continente, la creación o el desarrollo de comunidades de escritores de ciencia-ficción, de concursos, de revistas, de historias nacionales. Así, el crecimiento de una comunidad de lectores y escritores “expertos” en cienciaficción subraya la circulación “cerrada” del género, pero también hace patente la distancia con la que la literatura "general” trata al género.

6 La declaración con la que se cierra El fondo del cielo es elocuente en este sentido: “Antes que nada: esta no es una novela de ciencia-ficción. Esta [...] es una novela con ciencia-ficción” (263). Esta escrupulosa distinción condensa la relación de la literatura del período con la ciencia-ficción.

7 Según la famosa hipótesis de Isaac Asimov, el surgimiento de la ciencia-ficción debe relacionarse con la evidencia de que la tecnología tiene un impacto directo en la vida cotidiana 100-102. La aparición, en menos de diez años, de celulares, DVD, Internet, chat, etc., sugiere que probablemente no haya habido ninguna generación que haya sentido más que la presente el impacto de la tecnologización de la vida cotidiana.

Revista Iberoamericana, Vol. LXXVIII, Núms. 238-239, Enero-Junio 2012, $311-328$
ISSN 0034-9631 (Impreso) 


\subsection{Excurso por la narrativa latinoamericana}

En otro lugar hemos señalado que lo que caracteriza a la literatura producida a partir de los noventa es una dificultad para construir saber a partir del relato. En este sentido, la relación entre relato y saber (que puede rastrearse en la teoría desde Benjamin hasta Lyotard) se presenta como trunca: nada puede aprenderse por el relato porque todo ha sido aprendido antes de su inicio. ${ }^{8}$ De ahí que, por una parte, el saber devenga información y, por otra, el saber se torne un enigma que el lector debe resolver. Las formas de ese conocimiento y ese enigma permiten pensar tres posiciones centrales para la ficción contemporánea. ${ }^{9}$

La primera, que puede ejemplificarse (aunque con matices) en McOndo (1996), la antología preparada por los chilenos Sergio Gómez (1962) y Alberto Fuguet (1964), es aquélla que presenta una primera persona absorbente, concentrada en su propia vivencia que tiende a disolver la transformación de los episodios en "experiencia”, en la medida en que despliega saberes inmediatos relacionados, antes que por la relación causal, por el deambular más o menos azaroso de los protagonistas por el espacio urbano. ${ }^{10}$

Por otra parte, al tiempo que desestiman los ejes de la narración canónica, estos textos suman un tipo específico de saber que suele reforzar el efecto de inmediatez: son conocimientos ajenos a aquéllos esgrimidos por la literatura "culta": películas de clase B, música pop, programas de televisión, juegos de video. Esos saberes no requieren de otra explicitación que su mera mención y por lo tanto se presentan como contraseña: se presupone entonces un lector que sabe, porque pertenece al mismo espacio social, qué es Verdad, consecuencia (como se cita en Estocolmo [1998], del uruguayo Gustavo Escanlar) o qué significa que a un personaje le guste La lección de piano (como sucede en "Mi estado físico", el cuento del argentino Martín Rejtman, incluido en McOndo).

De esa naturalización deriva la transformación del saber en contraseña, que produce un efecto de "entre nos", que parece aislar al enunciatario y el enunciador. ${ }^{11}$ Así, el saber está puesto en función del efecto de continuidad entre los lectores y las voces narrativas. Esa continuidad vendría garantizada por la apelación constante a una jerga y un conjunto de referencias que, asociada a una instancia generacional, formularía una relación de re-conocimiento en la que sólo el enunciatario y el enunciador pueden comprender lo

8 Para las distinciones entre saber, información y conocimiento, ver Lyotard 43-57.

9 He desarrollado estas hipótesis de modo más extenso en De Rosso 50-63.

${ }^{10}$ Como se recordará, para Walter Benjamin la posibilidad de construir una "experiencia” se relaciona con la posibilidad de dar forma a un relato legible para la comunidad. En este sentido, el desasimiento de la estructura narrativa tiende a evitar la constitución de una experiencia (ver "El narrador. Consideraciones sobre la obra de Nicolai Leskov").

${ }^{11}$ Usamos el término "enunciación" y sus derivados en el sentido que le da Oscar Steimberg, como un "efecto de sentido de los procesos de semiotización por los que en un texto se construye una situación comunicacional” (42), que puede o no coincidir con un lector empírico.

ISSN 0034-9631 (Impreso) 
que se relata. Así, estas narraciones diseñan una imagen fragmentada de lo social en la que los saberes generacionales aparecen confirmados y se oponen a "los otros", los que no comparten ese saber. ${ }^{12}$

Una segunda forma es la que pueden encontrarse en novelas como Los impostores (2002), del colombiano Santiago Gamboa (1965) o “Imposibilidad delos cuervos” (1994), del mexicano Ignacio Padilla (1968). En estos textos se apela a saberes académicos que se exhiben para beneficio del lector. Es necesario entonces contextualizar, remitir a bibliografía en la última página. Si en el caso de los relatos de la contraseña se trataba de la construcción de una enunciación entre pares, aquí se genera una enunciación que refiere vagamente a una cultura compartida, pero que a la vez sugiere una enunciación didáctica, en la que el enunciador es una voz amable, que explica lo que el lector desconoce. ${ }^{13}$ Se trata aquí menos de construir un lector “académico” que de transformar a la academia en un lugar “amable”, pasible de aportar saberes que sirvan a una narración "bien contada”. Por eso las teorías y saberes más curiosos deben explicitarse, por eso si hay una referencia literaria ésta debe ser explícita. Así, esa voluntad de traducción de saberes resulta universalizante. De ahí que, salvo en contadas ocasiones, se imponga el respeto para tratar estos saberes. De ahí también que la prosa de estos relatos sea llana, sin localismos. Se trata, en verdad, de una profunda disimetría en la que aquel que sabe (la instancia narrativa) divulga al que no sabe (el lector) lo que descubrió en su recorrido por el mundo de la academia. ${ }^{14}$

Así, el saber es central en estos relatos, pero este saber es una tarea previa a la escritura, exhibe más la habilidad del experto para moverse en este orden que la posibilidad misma de producir o descubrir un orden. No existe, entonces, la construcción de un verdadero sujeto del conocimiento en la medida en que el relato se construye volcando categorías preconcebidas. Dado que es éste el sostén ideológico de estas ficciones, la conclusión lógica es una disociación entre saber y relato, porque el relato sucede alrededor

12 Esta línea, además, se caracteriza por la forma “laxa” de sus estructuras narrativas. En ellos, las acciones se suceden sin que haya necesariamente un nexo causal entre ellas o, mejor, produciendo un efecto de acumulación cuyo único contacto parece ser el recorrido más o menos errante de sus protagonistas. Esa tenue causalidad produce un efecto de desapego, de fragilidad. Así, estos relatos no concluyen, sólo terminan.

13 Ese gesto pedagógico distingue nítidamente estos textos de novelas como Respiración artificial (1980), de Ricardo Piglia (1940), o Morirás lejos (1964), de José Emilio Pacheco (1939), relatos también articulados sobre saberes académicos. En estos, a diferencia de los textos que aquí comentamos, se presupone un lector sabio, capaz de percibir las ironías sin apelar a explicaciones.

14 En muchos casos estos textos glosan el saber que convocan. En La traducción (1997), del argentino Pablo de Santis, existen conferencias y periodistas que convenientemente preguntan por las teorías de la traducción; En busca de Klingsor presenta largos parágrafos dedicados a explicar, con el tono de un informe científico, los descubrimientos de la física moderna. Se trata de ejemplos extremos, pero elocuentes: poco revelan a "los que saben” estos relatos de biblioteca.

Revista Iberoamericana, Vol. LXXVIII, Núms. 238-239, Enero-Junio 2012, $311-328$
ISSN 0034-9631 (Impreso) 
del saber y su posesión, pero rara vez es un relato sobre cómo se obtiene ese saber. ${ }^{15}$ En este sentido, resulta sintomático que En busca de Klingsor (1999), del mexicano Jorge Volpi, concluya con los delirios paranoicos del narrador, o que La obra literaria de Mario Valdini (2002), de Sergio Gómez, termine con la revelación de que la obra inconclusa que busca el académico protagonista es una copia manuscrita, la misma que Valdini había publicado treinta años antes.

En estas dos líneas, el saber se muestra como clausurado, vuelto información que intercambian de manera diversa el texto y el lector. Existe, sin embargo, la posibilidad de que esa clausura se exhiba como tal: que se la señale sin intentar salir de ella. La lectura de relatos como Los cautivos (2000), del argentino Martín Kohan (1967); Salón de belleza (1994), del peruano-mexicano Mario Bellatin (1960) o Que me maten si... (1997), del guatemalteco Rodrigo Rey Rosa (1958), deja la impresión algo incómodo, relacionado con la comprensión y el saber, y desacomoda el relato.

En efecto, aun cuando en estos relatos podamos encontrar un entramado narrativo “pleno” (como en Los cautivos o en "Pelando a Rocío”, un relato de Alberto Fuguet incluido en Sobredosis [1990]), los relatos se construyen sobre una carencia: el foco narrativo resulta insuficiente para revelar los sentidos del relato. Esos sentidos que, de ser articulados, transformarían al relato en "realista” permanecen elididos a lo largo del relato o bien excesivamente desarrollados. En La diabla en el espejo (1999), del salvadoreño Horacio Castellanos Moya, Olga María es una voz crispada que cuenta cómo su "mejor amiga” fue asesinada: esa voz, que destila orgullo de clase, que es maledicente y atolondrada para contar, parece la menos indicada para dar cuenta de los hechos. En Salón de belleza, por el contrario, todo el relato se construye con una voz seca y carente de emotividad que borra toda referencia espacial o personal. Así, se alude todo el tiempo a un episodio o a una figura ausente que existe más allá de la voz narradora y del foco narrativo: un episodio que guía los hechos pero que no puede explicarse a partir de los saberes que refiere la voz narradora.

En este sentido, estos relatos formulan una relación enunciativa diferente: no existe aquí ni la complicidad ni la docencia, estos relatos desafían al lector. En la medida en que se refieren a episodios específicos, reconstruidos con detalle pero nunca nombrados, se construye un lector que debe colegir más allá de lo narrado para dar sentido a los hechos. ${ }^{16} \mathrm{Y}$ es que los narradores de estos textos se nos presentan como distantes con

${ }^{15}$ A diferencia de lo que sucede en los relatos de la "contraseña", en estos textos el relato funciona plenamente, entre otras cosas, porque los saberes de biblioteca que el texto exhibe demandan un relato que explique su lugar en la cultura.

${ }^{16}$ No se trata aquí de "metarrelatos", de textos que explícitamente cuestionan la posibilidad de construir un relato o de "relatos cifrados", en los que "no se cuenta” y, sin embargo, por desplazamientos metafóricos se percibe aquello ausente. En los textos que nos ocupan, en cambio, el relato está lleno de peripecias y de "efecto de realidad" (en Salón de belleza se nos cuentan los rituales del travestismo y en "Pelando a

\footnotetext{
Revista Iberoamericana, Vol. LXXVIII, Núms. 238-239, Enero-Junio 2012, 311-328 ISSN 0034-9631 (Impreso) ISSN 2154-4794 (Electrónico)
} 
respecto a los hechos narrados (la "frialdad" de los narradores de Mario Bellatin es característica) o bien, si se trata de una primera persona, como ineficaces o insuficientes a la hora de contar qué sucede (es el caso de El arma en el hombre, de Horacio Castellanos Moya). Lo que se percibe es una especie de desacomodamiento frente al mundo que precede a la construcción del relato, y de la que el relato daría cuenta en su desfase entre narrador y enunciador. Así, en lugar de afirmar algún tipo de saber estos textos exhiben la ignorancia o la imprecisión y hacen del proceso de conocimiento parte esencial de sus estrategias narrativas.

Y si es posible afirmar que en estos relatos se cuestiona aquello que configura el eje de las narrativas de la contraseña y la biblioteca, habrá que decir que aun así, para estos relatos de la estupefacción, la capacidad de aprehender lo real por medio del relato también aparece como problemática.

\subsection{Excurso por la ciencia-ficción clásica}

Si se piensa de este modo, no resulta tan sorprendente la ausencia de relatos de ciencia-ficción en el corpus de la literatura contemporánea latinoamericana. En efecto, la escasez de relatos de ciencia-ficción puede derivarse de la dificultad para imaginar una escena enunciativa en la que la adquisición del saber pueda ser el centro del relato. En la medida en que en estos relatos el saber ya ha sido adquirido o bien el relato se construye sobre su ausencia la ciencia-ficción tiene problemas (al menos en sus formas más canónicas) para constituirse.

Y es que la ciencia-ficción se distingue de géneros cercanos (como el fantástico o el terror) porque, como ha señalado famosamente Darko Suvin, la ciencia-ficción es “un género literario cuyas condiciones necesarias y suficientes son la presencia y la interacción del extrañamiento y la cognición, y cuyo recurso formal más importante es un marco imaginativo distinto del ambiente empírico del autor” (30). Ese extrañamiento cognitivo sería el motor del género en el sentido de que "lo extraño" que en otros contextos permanece inexplicado; en la ciencia-ficción este extrañamiento encuentra una verosimilización en el modo en que una cultura imagina el trabajo científico (que puede resultar muy diferente del modo en que trabaja efectivamente la ciencia). ${ }^{17}$

Así, las más grandes piezas de la historia del género (desde las novelas de Wells hasta las de Philip K. Dick, pasando por “Una odisea marciana” [1934], de Stanley

Rocío”, se cuentan todos los detalles de la vida cotidiana de dos chicas "bien”). Lo que falta, lo que se percibe que falta, es la explicitación de la lógica que articula todos esos episodios.

17 Suvin superpone aquí los dos sentidos de "extrañamiento": aquel que refiere a lo extraño y aquel que refiere al "modo de ver” extraño (29). Ambas acepciones coincidirían en el modo en que Brecht imagina el discurso galileico.

Revista Iberoamericana, Vol. LXXVIII, Núms. 238-239,
ISSN 0034-9631 (Impreso) 
Weinbaum) intentan entender en términos racionales la diferencia entre ese mundo representado y el nuestro. Esa voluntad de comprensión distingue a la ciencia-ficción de la literatura en general y del relato fantástico en particular y permite entrar en un horizonte poco explorado de la definición de Suvin.

En efecto, lo que la ciencia-ficción configura en sus formas más clásicas (que son aquellas en las que se concentra Suvin) no es sólo un horizonte temático y una serie de procedimientos estructurales, sino también un pacto enunciativo en el que se propone un lector preocupado por entender esa diferencia. ${ }^{18}$

Esa escena enunciativa articula una ideología que resultó central para la configuración del género. En palabras de Fredric Jameson, por ejemplo, la diferencia entre fantasy y ciencia-ficción, derivada del impulso cognitivo el género, es el hecho de que:

si la CF es la exploración de todas las limitaciones que la historia se ha impuesto [...] entonces el fantasy es la otra cara de la moneda, y una celebración del poder creativo de la humanidad que se torna idealista justamente en virtud de la omisión de esas limitaciones históricas y materiales. (66; mi traducción)

Así presentada, la ciencia-ficción es un género historicista, preocupado por el modo de producción (de tecnología, de bienes, de subjetividades, etc.) propio de una cultura. Sin ese marco conceptual, que se relaciona con el tipo de saber que busca la cienciaficción, resulta difícil imaginar algunos de los rasgos centrales de la ciencia-ficción más tradicional: la maravilla del descubrimiento, el imperio galáctico, la utopía y la distopía, etc.

En este punto, la naturalización del saber social (o su ominosa ausencia), central para la literatura latinoamericana contemporánea, bloquea el impulso cognitivo del relato tradicional de ciencia-ficción e impide la apropiación de sus modos para la construcción de relatos.

\section{TRES NOVELAS}

Tal vez el mejor modo de estudiar la relación entre la ciencia-ficción y la literatura latinoamericana contemporánea sea estudiar algunos relatos que fueron asociados a ella en diversos metadiscursos. ${ }^{19}$ Esa asociación tal vez permita ver en qué sentido se puede

${ }^{18}$ El dispositivo más sencillo para articular esa demanda era la figura de un personaje a quien se le explica en algún momento de la trama qué era lo que pasaba.

${ }^{19}$ Los géneros son categorías históricas, y como tales, fijan su sentido en una relación históricamente determinada. Escribir sobre ciencia-ficción requiere, por lo tanto, verificar los modos en que un conjunto de textos es agrupado por otros discursos (sus metadiscursos) en una misma categoría. Ver Steimberg 37-38.

\footnotetext{
Revista Iberoamericana, Vol. LXXVIII, Núms. 238-239, Enero-Junio 2012, 311-328 ISSN 0034-9631 (Impreso) 
hablar de ciencia-ficción, pero también en qué sentido estas novelas se distinguen de la actual producción literaria del continente. Trataremos aquí con textos cuya adscripción ha sido inestable: los libros se han publicado en colecciones generales y gran parte de la crítica que a ellos se ha dedicado no menciona el hecho de que se trate de relatos de ciencia-ficción. ${ }^{20}$ Así, en primera instancia, el emplazamiento de Las islas (1998), del argentino Carlos Gamerro (1962), El delirio de Turing (2003, reeditada con correcciones en 2005), del boliviano Edmundo Paz Soldán, y El exilio según Nicolás (2004), del uruguayo Gabriel Peveroni (1969), sugiere que estas novelas, a la vez, pertenecen y no pertenecen al género. $\mathrm{O}$ mejor: que existen en ellas algunos elementos que permiten inscribirlas en él y otros que de alguna manera contradicen esa inscripción. Esa discordia es el punto de partida de este trabajo. Algo, sugiere la crítica, asemeja estos textos a la ciencia-ficción, aún cuando aparentemente ninguno de sus rasgos señala obligadamente esa relación. ${ }^{21}$

Más aún, los metadiscursos producidos por los mismos escritores sugieren una inestabilidad constitutiva. Carlos Gamerro, por ejemplo, sugiere que en la literatura argentina posterior a los ochenta "[c]iencia-ficción, literatura fantástica y realismo empiezan a fundirse en un continuo hiperrealista” ("La imaginación”), y Paz Soldán señala que "Hoy no hay novela realista que no juegue con algunas de las convenciones del género policial, ni que explore un tema o arriesgue un párrafo o una especulación que décadas atrás hubiera estado confinada a la ciencia-ficción” ("Más allá”). Así, podríamos decir que nos encontramos con una aparente paradoja: los escritores afirman escribir novelas realistas, y la crítica afirma, al menos en algunas instancias, que escriben novelas de ciencia-ficción. Entre ambos discursos están las novelas y, sobre todo, lo que probablemente sea el eje de la distinción entre realismo y ciencia-ficción en este contexto: la incorporación de tecnología a tramas realistas.

Así es que para estudiar ese desfase tal vez sea necesario volver a la ciencia-ficción (como, por otra parte, sugieren tanto Gamerro como Paz Soldán) menos porque los textos pertenezcan a ese género, sino antes bien, porque parecen evocarlo y las formas de esa evocación tal vez nos permitan entender la circulación de esas novelas, esa "cienciaficcionalidad" inscripta en su "realismo tecnológico".

${ }^{20}$ Elsa Drucaroff ha señalado en Las islas la tensión entre ciencia-ficción y relato policial; Andrea Blanqué presenta El exilio según Nicolás como: "Ciencia-ficción en un Montevideo mediocre y reconocible"; Alvaro Bisama afirma que en sus novelas "Paz Soldán escribe de nuestra cultura como una cienciaficción casi cotidiana” (31). En todos los casos aparece una incomodidad para adscribir estas novelas a la ciencia-ficción.

${ }^{21}$ Notablemente, en la mayoría de los casos, esa adscripción permanece inexplicada en las reseñas, como si se tratara de una impresión difusa cuyas marcas textuales resultan difíciles de señalar.

\footnotetext{
Revista Iberoamericana, Vol. LXXVIII, Núms. 238-239, Enero-Junio 2012, 311-328 ISSN 0034-9631 (Impreso) ISSN 2154-4794 (Electrónico)
} 


\section{DeSPuÉS DE LOS CLÁSICOS}

Uno de los efectos menos estudiados de la renovación de la ciencia-ficción en la década del sesenta (conocida como la "new wave" -textos de James Ballard, Barry Malzberg, Thomas Disch) fue el modo en que se desactivó el impulso cognitivo característico de la ciencia-ficción.

Quien primero lo vio, el profeta del fin del futuro, fue James Ballard. A comienzos de la década del sesenta Ballard había visto (y vociferado) que el futuro de la cienciaficción era la “exploración del espacio interior” (“¿Cuál es el camino?” 78). Lo que importaba (lo que comenzó a ser cada vez más importante) de la ciencia-ficción era su posibilidad de evocar imágenes que se habían filtrado en nuestro inconsciente y, por lo tanto, se habían transformado en parte de nuestro modo de percibir.

Los cuentos que por aquellos años escribe Ballard son relatos en los que el horizonte de la ciencia-ficción aparece como un escenario, como un marco para la acción, pero ya no como un modo de procesar el extrañamiento que comporta. Lo que Ballard construye en libros como El hombre imposible (1966) o La exhibición de atrocidades (1973) es una especie de Disney World apocalíptico en el que los personajes visitan displicentes las diferentes posibilidades de la catástrofe que la ciencia-ficción ofreciera (sobre todo en Inglaterra) en años previos.

Pero algo se echa en falta en los textos de Ballard. Lo que cambia definitivamente cuando se incorpora Ballard (o Barry Malzberg o lo mejor de John Sladek) al universo de la ciencia-ficción es la narración de la maravilla. De alguna manera esto había sido notado por la generación previa de escritores de ciencia-ficción (Philip Dick, Alfred Bester, William Tenn), para quienes el futuro ya no era radicalmente diferente de nuestro presente. Sin embargo, para ellos todavía había alguna diferencia: universos con extraterrestres y mundos paralelos con naves espaciales y sueños lúcidos descriptos con el vigor de una razón desbocada. Con la "nueva ola” de los sesenta, en cambio, desaparece el énfasis y la sensación de que lo que se cuenta es extraño o amenazante. La ciencia-ficción se tornó entonces una escenografía en la que no era necesario comprender nada, ni nada era sorprendente, porque el mundo había perdido sentido. La indiferencia se vuelve el tono narrativo. Pensado en términos de Suvin, lo que gana el escenario es el "marco imaginativo distinto del ambiente empírico del autor”, antes que el componente cognitivo.

Ese marco ya no admite la posibilidad de que la tecnología pueda “explicar” los hechos o de que se los pueda detener o cambiar. En este sentido, puede afirmarse que el pacto enunciativo del género cambia de forma. Ya no hay una continuidad entre el foco narrativo y la figura del lector: mientras que para el primero lo extraño se ha tornado cotidiano, para el segundo el mundo representado permanece extraño.

La ciencia-ficción se torna entonces un decorado para la catástrofe. Y no hay mejor muestra del triunfo de esta concepción del género que el éxito del cyberpunk. En efecto,

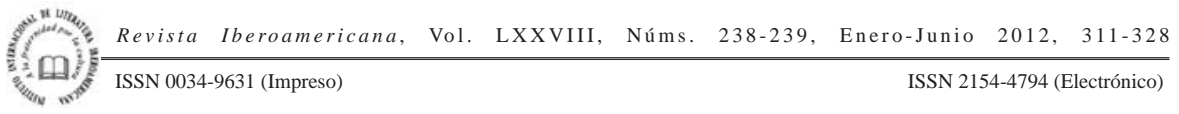


aunque se ha querido ver en el movimiento (que gana visibilidad con la publicación en 1984 de Neuromancer, de William Gibson, y en 1986 de Mirrorshades, la antología preparada por Bruce Sterling), una regresión de los modos de la ciencia-ficción, en verdad los cyberpunks son el producto del desarrollo mismo del género. Puede afirmarse, por ejemplo, que la atención a las diferencias entre realidad e ilusión, el uso pirotécnico del lenguaje y la atención a las transformaciones del cuerpo son elementos que existían mucho antes (en la obra de Dick, de Bester, de Theodore Sturgeon) de la aparición del cyberpunk. También puede decirse que el "desdén cognitivo" con el que el cyberpunk describe la novedad tecnológica puede encontrarse en la "nueva ola" de los sesenta de la que, en realidad, los escritores del cyberpunk son sus más fulgurantes deudores. Esos elementos, como veremos, se combinan de una manera inédita para la historia del género y tal vez en esa combinación radique el éxito del movimiento.

La más evidente novedad que trajo el cyberpunk a la ciencia-ficción fue temática. En efecto, de lo que se trata en las novelas de Gibson (pero también en los cuentos de Crystal Express [1989], de Sterling, o Software [1982], de Rudy Rucker) es de la construcción de un nuevo referente, que condensó en una palabra inventada en Neuromante: el ciberespacio. Los héroes del cyberpunk eran "jinetes de la consola", traficantes de información, héroes de un futuro en ruinas. Esa heroicidad depende de un nuevo modo de concebir la forma de la política: el verdadero poder reside en controlar las redes y, por lo tanto, el mundo que representan las novelas cyberpunk ha abdicado de la idea de Estado o de policía. Los estilizados personajes de estas novelas y cuentos lidian con corporaciones multinacionales y matones a sueldo, y todo triunfo es efímero porque, en el fondo, parece imposible oponerse a su poder omnímodo. En este sentido, como ha señalado John Clute ("Science fiction” 72), lo que resulta característico del cyberpunk (lo que tal vez la ha granjeado su popularidad en la escena contemporánea) es la sensación de que los personajes son a la vez todopoderosos e inermes, que pueden entrar a cualquier red informática, pero que no pueden entender del todo por qué se les pide que lo hagan. De ahí que lo que gana la escena en el cyberpunk es el orden global como conspiración.

En este sentido, comparado con los experimentos de los sesenta (la disolución de la trama en Ballard y en novelas de Brian Aldiss como Informe sobre la probabilidad A [1968], la utilización de la estructura de collage en Todos sobre Zanzíbar [1968], de John Brunner, el uso de una estructura narrativa combinatoria en 334 [1972], de Thomas Disch), los textos cyberpunk hacen reentrar la narración más tradicional en la ciencia-ficción (tramas lineales, personajes psicológicos, etc.), pero cambian el eje del relato. Con el cyberpunk los enigmas se desplazan de la ciencia (o de los misterios de la vida extraterrestre) a los poderes que manejan a los personajes.

Existe, sin embargo, otra forma de imaginar el cambio que trae el cyberpunk a la ciencia-ficción. Peter Nicholls ha señalado que lo que caracteriza al género es su densidad informacional: la cantidad de información que requiere la lectura de una novela cyberpunk

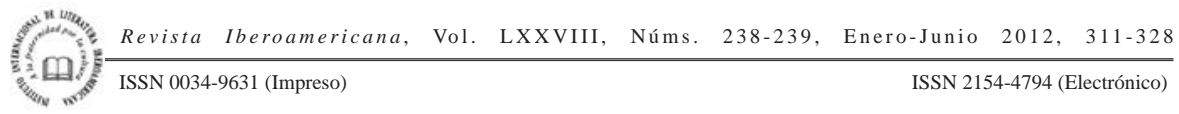


(288). Este hecho puede relacionarse con la disimetría enunciativa que señalábamos antes: en la medida en que la narrativa cyberpunk no pretende explicar la diferencia con el mundo representado, sino sólo mostrarlo, la prosa abunda en referencias oscuras a episodios, a tecnología o inclusive a usos y costumbres desconocidos para un lector que sólo puede comprenderlos a medida que el relato se desarrolla.

El hecho es cualitativamente diferente de las narraciones de la "new wave” en la medida en que aquellas pretendían producir imágenes novedosas que se refirieran a un nuevo estado de la conciencia antes que a un estado de la evolución tecnológica. Y aún si esto puede afirmarse del cyberpunk (particularmente de Gibson y Rudy Rucker), también es cierto que esas imágenes del ciberespacio aparecen atravesadas por una serie de referencias a la tecnología y al consumo particularmente densa. En este sentido, si la "new wave" liberaba a la ciencia-ficción de la tecnología, el cyberpunk transforma a la tecnología en jerga y a las imágenes de la catástrofe en objetos de consumo. ${ }^{22}$ Como señala Clute, los personajes del cyberpunk han dejado de ser creadores (casi no se encuentran científicos en estos relatos), para ser consumidores ("William Gibson” 493).

Esa variación sugiere una imposibilidad de imaginar el cambio, que bien puede relacionarse tanto con la idea de conspiración como con el desplazamiento del futuro lejano al futuro cercano, otro rasgo característico de la tendencia. ${ }^{23}$ En efecto, el futuro no sólo ha dejado de ser acogedor (un tema que ha caracterizado a la ciencia-ficción al menos desde La máquina del tiempo [1895] de Wells) sino que también ha dejado de parecer futuro. ${ }^{24}$ No sólo se trata de que las ficciones se han desplazado sólo unos pocos años hacia adelante, sino que el futuro se nos muestra como una especie de presente intensificado por parafernalia futurista. Así, todo sucede como si la ciencia-ficción hubiera encontrado en el cyberpunk el límite de sus fuerzas creativas: despojado de impulso cognitivo y de imaginación política, la ciencia-ficción en el cyberpunk ha dejado de ser una forma de imaginar el futuro. ${ }^{25}$

En ese punto, tal vez, el cyberpunk se ha tornado una de las formas más productivas de la ciencia-ficción. Porque si por una parte representa un límite para el género, por

${ }^{22}$ Fredric Jameson ha mostrado cómo el cyberpunk transforma los objetos en marcas, que circulan como categorías osificadas en el relato (“Fear and loathing” 386-87).

${ }^{23}$ Slavoj Žižek ha señalado en qué medida las fantasías conspiran con el producto de un mundo incomprensible, de una cultura que se imagina impotente para el cambio político (182-86).

${ }^{24}$ Notablemente, el otro desarrollo mayor del género en los años posteriores a los ochenta es una vuelta al planetary romance. Esto es, un retorno a la imaginación de futuros extraordinariamente lejanos que, en un sentido, desplazan el interés de la historia a la antropología, como lo hacen Un fuego sobre el abismo (1992), de Vernor Vinge o la saga de El libro del sol largo (1993-1996), de Gene Wolfe.

${ }^{25}$ En este sentido puede entenderse que tanto Jameson ("The Great Schism" 68) como Clute ("Science fiction” 66-68) vean el éxito del fantasy, un fenómeno contemporáneo del cyberpunk, como la prueba del fracaso de la ciencia-ficción para lidiar con la sensibilidad contemporánea.

ISSN 0034-9631 (Impreso) 
la otra le ha permitido a la ciencia-ficción articularse con una variedad impensada de procedimientos. El hecho, por ejemplo, de que Cruptonomicon [1999], de Neal Stephenson, sea considerada un relato de ciencia-ficción sugiere que los temas de la ciencia-ficción y su capacidad para el extrañamiento tecnológico se funden con rasgos propios de otros géneros, los tiñen o se los apropian.

$\mathrm{Y}$ es tal vez en ese sentido que pueda pensarse que la matriz del cyberpunk, ahora despojada de todo futuro, pueda ser una matriz para la narrativa contemporánea latinoamericana. Y es que la “densidad informacional” característica de la prosa cyberpunk puede también pensarse como información naturalizada. Esa naturalización se mueve en el horizonte de la presuposición, se presenta como "ya-adquirida” y el relato poco hace por estudiar su origen. Ese modo de presentar el saber es característico de la literatura latinoamericana que comienza a escribirse durante los noventa: todo saber ya ha sido apropiado y se transforma en contraseña o en enciclopedia, o bien se lo da por perdido para el texto. Poco importa en este punto si esa información es tecnológica: los modos enunciativos de la literatura contemporánea latinoamericana pueden cruzarse con ellos aún cuando no se refieran a los mismos objetos.

\section{LA INFORMACIÓN}

Si la crítica ha encontrado en Las islas, El delirio de Turing y El exilio según Nicolás rastros de la ciencia-ficción es porque algunos rasgos del cyberpunk aparecen en ellas. ${ }^{26}$ Por una parte, la naturalización de la información tecnológica: qué es el Chat, cómo funciona la red de redes cuáles son las posibilidades de los virus de computación son a la vez materia inédita en la ficción latinoamericana hasta la década de los noventa y saberes que circulan en el tejido social y del que los narradores y focos narrativos no se ven obligados a dar cuenta. Ese doble emplazamiento (la "novedad" literaria y la cotidianeidad de su condición extraliteraria), sumadas al referente tecnológico en que anclan, contribuye a su asociación a la ciencia-ficción y, en particular, al cyberpunk.

En este sentido, como en el cyberpunk, los protagonistas de estas novelas son consumidores de tecnología antes que creadores en el sentido cabal del término: tanto en El exilio según Nicolás como en El delirio de Turing, los personajes navegan en redes ya diseñadas, con programas ya escritos; por otra parte en Las islas, Felipe debe crear un videojuego, pero para hacerlo recicla soldados y armamento de juegos previos. Para estos personajes el ciberespacio se ha convertido en una segunda naturaleza, inalterable, en la que medran.

${ }^{26}$ En el caso de Paz Soldán y Peveroni esa relación ha sido explicitada por Montoya Juárez (540). Brown pone en relación las novelas de Gamerro y Paz Soldán a través de la noción de "hacker", entendida como figura mediadora entre lo humano y las redes de información. Esa mediación tiene como horizonte literario al cyberpunk.

$\begin{array}{lllrl}\text { ISSN 0034-9631 (Impreso) } & \text { ISSN 2154-4794 (Electrónico) }\end{array}$ 
Sin embargo, ese uso de la tecnología de la información viene acompañado, como en la ciencia-ficción, de una sospecha constitutiva. En efecto, tanto en Las islas como en El delirio de Turing la trama se teje alrededor de conspiraciones que asimilan el relato a los modos del relato policial. ${ }^{27}$ En el caso de El exilio según Nicolás se sospecha que uno de los participantes de un juego virtual, Vidas cruzadas, está asesinando a los otros jugadores. Más aún, en todos los casos la sospecha atraviesa el campo de lo social, su orden se ha tornado opaco para aquellos que acceden a la tecnología. ${ }^{28}$ Así, si en otros relatos la tecnología aparece como elemento de verosimilitud, una nueva forma de la relación (tecnológica) entre individuos (el uso del Chat en las Kerés kojer?= Guan tu fak? (2005), del argentino Alejandro López [1968]) el reemplazo de la carta por el mail en El corazón de Voltaire (2005), del puertorriqueño Luis López Nieves [1950]), aquí aparece como un elemento opaco, cuyas implicaciones no pueden preverse. Esa vacancia de sentido para las tecnologías de la información, la sospecha sobre sus usos, acerca estas novelas al universo de la ciencia-ficción y las aleja de su uso en otros relatos contemporáneos. ${ }^{29}$

Notablemente, la información que circula en estas novelas tiene un rango acotado: se trata en todos los casos de información sobre la identidad. En Las islas, Felipe Félix busca una lista de testigos; en El delirio de Turing los esfuerzos de la Cámara Negra están dedicados a encontrar a Kandinsky; y Vidas cruzadas se desenvuelve como un reality show on line en el que se van dando a conocer las personalidades de los jugadores (y se van descubriendo, también, sus imposturas). Pero si bien este uso de la tecnología acerca estas novelas a la narrativa cyberpunk, en ellas no se trata sólo de afirmar que es imposible conocer las derivaciones de la tecnología, de comprobar que toda información puede ser objeto de múltiples manipulaciones, de verificar que la identidad es un objeto privilegiado de esta indagación. Por el contrario, en estas novelas esos usos tienen consecuencias impredecibles para algunos puntos nodales del tejido mismo del relato.

27 En Las islas se trata de encontrar a los testigos de un crimen, en El delirio de Turing de encontrar a un hacker, Kandinsky, que boicotea los planes de la política globalizadora del gobierno.

28 En el caso de la novela de Peveroni, el encierro del protagonista y la peste que avanza sobre la ciudad hacen crecer la sospecha de manejos turbios por parte del gobierno.

29 En este sentido, es ejemplar el conflicto que se desata en El exilio según Nicolás: entre los objetivos con los que Nicolás redacta las reglas de Vidas cruzadas está la de “evitar dos situaciones posibles: la renuncia de uno o más jugadores [...] y el travestismo epistolar, situación tan común e irritante propia de las salas de amigos virtuales” (20). Todo el conflicto de la novela, podría decirse, deviene de la imposibilidad de cumplir ninguna de las dos reglas (sobre todo la segunda): a lo largo del texto casi todas las identidades virtuales son usurpadas, al punto de que es casi imposible seguir los diversos "travestismos epistolares" que aparecen en sus páginas. Ese, claro, parece ser el punto central del argumento de la novela sobre la tecnología. La tesis había sido adelantada en “El doctor Ash está un poco loco”, de 1997. La sustitución de identidades es también un tema central de la novela de Paz Soldán, así como el uso criminal de la información está en el eje de la novela de Gamerro.

Revista Iberoamericana, Vol. LXXVIII, Núms. 238-239, Enero-Junio 2012, $311-328$
ISSN 2154-4794 (Electrónico) 


\section{LA INDETERMINACIÓN}

Si el cyberpunk, en comparación con la forma del relato que caracterizó a la "new wave”, representa una vuelta a las formas más tradicionales del relato de ciencia- ficción, habrá que señalar también que, con toda su prédica sobre la formación de una nueva humanidad armada con prótesis y chips, la tendencia representa una vuelta a la distinción sujeto/mundo que caracterizó a la literatura realista decimonónica. ${ }^{30}$

Para los relatos que nos ocupan, por el contrario, esa distinción se torna inestable. En efecto, los personajes que trafican con las redes terminan perdiendo toda certeza sobre el sentido de sus acciones. Hacia el final de Las islas es imposible saber si Felipe es una variable contemplada de la conspiración que se supone desbarata. En El delirio de Turing uno de los protagonistas descubre que ha sido manipulado por una dictadura para creer que es un genio del criptoanálisis. En la segunda parte de El exilio según Nicolás el protagonista recapitula su vida, sin orden ni concierto, como si su identidad estuviera en proceso de descomposición. No se trata aquí de engaños, del error en el juicio de los enemigos y de los amigos, sino más bien del cuestionamiento de la misma posibilidad de conocer y evaluar esas relaciones.

Esa puesta en crisis de la subjetividad resulta correlativa de una lógica narrativa que expone puntos ciegos a los que el texto no logra acceder. Nunca se sabe, por ejemplo, quién es Kandinsky en la novela de Paz Soldán, ni quién es el hombre que murió en las torres de Tamerlán en la novela de Gamerro, ni quién chatea con el nick 32800832 en la novela de Peveroni. ${ }^{31}$ Esos puntos ciegos son significativos porque sugieren que la indeterminación que corroe la subjetividad de los protagonistas es constitutiva del texto y que, finalmente, no es posible el acceso pleno a la información. La ilusión del cyberpunk queda para siempre delimitada por una línea de sombra.

Pero si el estatuto acordado a la información en la narrativa cyberpunk aparece cuestionado por estos relatos, también el tejido narrativo parece sujeto a una erosión que lo aleja del clasicismo narrativo. Así, no sólo nunca sabremos quién es Kandinsky, con lo que los elementos de novela policial que sostienen gran parte de la novela de Paz Soldán parecen girar en el vacío; también en Las islas Felipe deja de contar y su lugar es tomado por una sobreviviente de las torturas de la dictadura argentina que cuenta una

${ }^{30}$ Ballard ha señalado en qué medida la narrativa clásica de ciencia-ficción es deudora de la narrativa decimonónica (ver "Notas de ninguna parte”).

${ }^{31}$ Las islas, además, avanza en otra dirección. En El delirio de Turing y El exilio según Nicolás lo inexplicable permanece como punto ciego y los personajes no hacen nada por explicarlo (entre otras cosas porque es una operatoria del texto y no de sus conciencias). Así, la verdad se torna opaca y, en el fondo, negativa: es imposible conocerla. En Las islas, ese régimen de verdad (el de la verdad racional que exige comprobación) es reemplazado por otro (la verdad pasional que exige fidelidad). En verdad, podría decirse que el punto central de la novela de Gamerro es el descubrimiento de esa nueva forma de la verdad.

Revista Iberoamericana, Vol. LXXVIII, Núms. 238-239, Enero-Junio 2012, $311-328$
ISSN 0034-9631 (Impreso) 
fábula en la que todos los elementos de la novela son reordenados. En El exilio según Nicolás el "final feliz” es impredecible (el protagonista parece estar feliz al reencontrarse con su ex novia, pero termina, también feliz, con otra mujer) y, en el fondo, azaroso, como si las mujeres fueran intercambiables para la lógica del texto. Podría entonces afirmarse que así como la conciencia y el saber encuentran un límite, así también el relato lo encuentra, como si, agotado por los vaivenes de la trama, finalmente fuera necesario cambiar las coordenadas (o desentenderse de ellas) para concluir el relato. ${ }^{32}$ Esos movimientos de la estructura narrativa están relacionados con los modos en que se usa la tecnología en el relato, con las incertezas que trae aparejado su uso (y con la confianza más o menos excesiva que muestran los usuarios), pero también con las formas del relato que exhibe la literatura latinoamericana de estos años. ${ }^{33}$

Ese agotamiento también es el agotamiento de un modo de entender el espacio urbano. En estos relatos la ciudad se ha vuelto un espacio amenazante que los protagonistas hacen todo lo posible por evitar. El relato de las visitas a la Facultad de Verterinaria y a la SIDE que realiza Félix, la ciudad a oscuras que recorre Ruth en El delirio de Turing, y el Montevideo cercado por la peste del que se exilia Nicolás son formas de retratar una ciudad enemiga de la que los personajes escapan para alcanzar la seguridad ilusoria del ciberespacio. Y esta seguridad es ilusoria menos porque los peligros también existan en el ciberespacio que porque la espacialidad que describen estas novelas sugiere que es necesario volver a la ciudad para que el relato tome forma. Como si las posibilidades del mundo virtual fueran limitadas y su agotamiento obligara a volver a la ciudad. ${ }^{34}$

\section{OTRA FORMA DE SABER}

Como señalamos antes, no se trata aquí de verificar el acomodamiento de estos relatos a una estética como la del cyberpunk, pero sí, tal vez, de explicarse cómo es que un estilo literario refractario a los modos de la ciencia-ficción ha producido en los últimos años algunas novelas que fueron identificadas ocasionalmente como ciencia-

32 En este sentido, los textos de Peveroni y Paz Soldán producen un efecto de futilidad. Como si, de alguna manera, lo importante fuera llegar hasta ese punto, como si la intriga, en términos estructurales, fuera independiente de la resolución: importa cómo se busca a Kandinsky, importan los devaneos amorosos de Nicolás. Quién es Kandinsky o con quién se queda Nicolás son cuestiones secundarias y, en el fondo, irrelevantes para la construcción del texto.

${ }_{33}$ Beatriz Sarlo (475-76) ha descrito el fenómeno del "abandono de la trama" en ciertas novelas argentinas contemporáneas.

${ }^{34}$ Existen diferencias entre las formas en que es posible recuperar el espacio urbano. En El delirio de Turing se trata de la pacificación del mundo político tras la (falsa) detención de Kandinsky; en El exilio según Nicolás, de la reconciliación del protagonista con sus amigos; en Las islas no hay pacificación posible en la ciudad, pero tampoco en el espacio tecnológico, por lo que resulta necesario un tercer espacio, el cuerpo de una mujer en una casita de Parque Chas (un barrio laberíntico de Buenos Aires).

ISSN 0034-9631 (Impreso) 
ficción. Se trata de un cruce que tal vez no produce novelas de ciencia-ficción, pero que convoca algunos de los modos más frecuentes del cyberpunk (y de ahí provendría su identificación inestable con la norma genérica).

Podría entonces afirmarse que esa adscripción inestable ha producido objetos curiosos que, sin despegarse de las líneas centrales que hemos descripto más arriba, se distinguen de las tendencias principales de la ficción "general” producida en América Latina.

Por una parte, se trata de textos que, a partir del uso de las tecnologías de la información, vuelven inestables las categorías que en relatos contemporáneos parecen inconmovibles. En las novelas que mencionamos el foco narrativo se vuelve poroso, los personajes, que parecen no aprender nada en otros textos de la época, aquí comprometen su identidad, tienden a la disolución en el contacto con esa tecnología, y el resultado de esas incursiones en el ciberespacio tienen como consecuencia menos un cambio en el mundo que un cambio en la propia subjetividad. En el mismo sentido, la estructura narrativa es vivencia sin experiencia, el relato pleno de la biblioteca o el relato vacío del estupor, que la construcción de un relato pleno, lleno de peripecias al que súbitamente le falta el final que el texto parece proponer.

Esa variación estructural tiene, por otra parte, un correlato en los modos del saber. En efecto, estos relatos pueden leerse como variantes de las tres líneas que parecen definir la narrativa contemporánea latinoamericana. Sin embargo, aquí el uso de la tecnología (y de las estrategias de la ciencia-ficción) vuelve esos saberes en materia de discusión. Estas novelas trabajan con esos saberes naturalizados, pero también exploran sus causas y consecuencias. Aquí la duda y la paranoia sobre la tecnología permiten volver a pensar las formas de sociabilidad contemporánea que otros relatos dan por sentada (El exilio según Nicolás), las formas de la intervención política (El delirio de Turing) que otros consideran inverosímil, y las formas de la verdad que otro consideran inamovibles (Las islas). Se pregunta, en fin, para qué sirve el saber (que otros dan por sentado y otros, aun, por perdido) en la narrativa contemporánea.

Tal vez por otros medios, tal vez con otros fines, ése fue siempre el objeto de la ciencia-ficción.

\section{BIBLIOGRAFÍA}

Amar Sánchez, Ana María. “Ciudades desiertas: fin de siglo, pop y desencanto”. Juegos de seducción y traición. Literatura y cultura de masas. Buenos Aires: Beatriz Viterbo, 2000. 154-66.

Asimov, Isaac. "Ciencia-ficción y sociedad”. Sobre la ciencia-ficción. Buenos Aires: Sudamericana, 1982. 100-8.

Ballard, James. “¿Cuál es el camino al espacio interior?” Artefacto 4 (oct. 2001): 77-79. “Notas de ninguna parte”. El péndulo 1 (mayo 1981): 77-80.

\footnotetext{
Revista Iberoamericana, Vol. LXXVIII, Núms. 238-239, Enero-Junio 2012, 311-328 ISSN 0034-9631 (Impreso) ISSN 2154-4794 (Electrónico)
} 
Becerra, Eduardo, ed. Líneas aéreas. Madrid: Lengua de trapo, 1999.

Benjamin, Walter. "El narrador. Consideraciones sobre la obra de Nikolai Leskov". Sobre el programa de la filosofía futura. Barcelona: Planeta-De Agostini, 1986. 189-211.

Bisama, Álvaro. “Tecnología y ficción”. Literal. Latin american voices 17 (verano 2009): 31.

Blanqué, Andrea. "De ciencia-ficción”. Freeway. Julio 2005. < http://exiliomediatico. blogspot.com/> 10 feb. 2010.

Brown, J. Andrew. "Hacking the Past: Edmundo Paz Soldán's El delirio de Turing and Carlos Gamerro's Las Islas”. Arizona Journal of Hispanic Cultural Studies X (2006): 115-129.

Castellanos Moya, Horacio. El arma en el hombre. Barcelona: Tusquets, 2001.

Clute, John. "Science Fiction from 1980 to the Present". The Cambridge Companion to Science Fiction. Edward James y Sarah Mendlesohn, eds. Nueva York: Cambridge UP, 2003. 64-78.

"William Gibson”. The Encyclopedia of Science Fiction. Nueva York: St. Martin’s Griffin, 1995. 493-494.

De Rosso, Ezequiel. Nuevos secretos: transformaciones del relato policial en América Latina. 1990-2000. Tesis doctoral. Universidad de Buenos Aires, 2009.

De Santis, Pablo. "Lo audaz de Avatar es plantear el paraíso". Clarín (30 enero 2010). Clarin.com 13 feb 2010. <http://edant.revistaenie.clarin.com/ notas/2010/01/30/_-02129039.htm>.

Drucaroff, Elsa. "Narraciones de la intemperie”. El interpretador 27 (junio 2006). <http://www.elinterpretador.com.ar/ensayos_articulos_entrevistas-numero27junio2006.htm>. 14 feb. 2010.

Fornet, Jorge. Los nuevos paradigmas. La Habana: Letras Cubanas, 2006.

Fresán, Rodrigo. El fondo del cielo. Buenos Aires: Mondadori, 2009.

Fuguet, Alberto y Sergio Gómez, eds. McOndo. Barcelona: Grijalbo, 1996.

Gamerro, Carlos. "La imaginación tecnológica al poder". Oliverio 11 (2005). <http:// www.ciudaddearena.org/025-gamerro03-tecnologica.html>. 8 mar. 2008.

Las islas. Buenos Aires. Simurg, 1998.

Gibson, William. Newromancer. Nueva York: Ace Books, 1984.

Jameson, Fredric. "Fear and Loathing in Globalization". Archaeologies of the Future. Nueva York: Verso, 2007. 384-92.

“The Great Schism”. Archaeologies of the Future. Nueva York: Verso, 2007. 57-71.

Lyotard, Jean François. La condición posmoderna. M. Antolin Rato, trad. Madrid: Cátedra, 1987.

Montoya Juárez, Jesús. "Exilios virtuales en la era de lo transnacional: El exilio según Nicolás, de Gabriel Peveroni”. Realismo del simulacro: imagen, medios ytecnología en la narrativa del Río de la Plata. Tesis doctoral, Universidad de Granada, 2008.

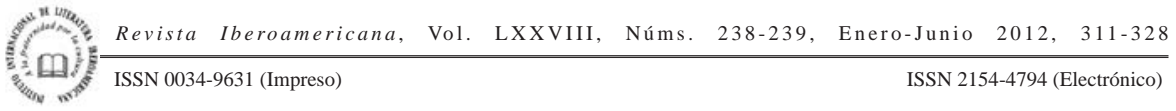


Granada: Editorial Universidad de Granada, 2008. 540-551. <http://hera.ugr.es/ tesisugr/17679254.pdf>. 10 feb. 2010.

Nicholls, Peter. "Cyberpunk”. The Encyclopedia of Science Fiction. Nueva York: St. Martin’s Griffin, 1995. 288-90.

Ortega, Julio, comp. Las horas y las hordas. Antología del cuento latinoamericano del siglo XXI. México: Siglo Veintiuno, 1997.

Paz Soldán, Edmundo. "Más allá de la ciencia- ficción”. La Prensa. 21 sept. 2003. $<$ http://www.sololiteratura.com/edm/edmmasalladela.htm> 14 feb. 2010.

El delirio de Turing. Buenos Aires: Alfaguara, 2005.

y Alberto Fuguet, sel. Se habla español. Voces latinas en USA. Miami: Alfaguara, 2000.

Peveroni, Gabriel. “El doctor Ash está un poco loco”. Pequeñas resistencias. Antología del nuevo cuento sudamericano. J. C. Chirinos y otros, eds. Madrid: Páginas de Espuma, 2004. 355-58.

El exilio según Nicolás. Montevideo: Santillana, 2004.

Sarlo, Beatriz. "La novela después de la historia. Sujetos y tecnologías”. Escritos sobre literatura argentina. Sylvia Saítta, ed. Buenos Aires: Siglo XXI, 2007. 471-82.

Steimberg, Oscar. “Proposiciones sobre el género”. Semiótica de los medios masivos. Buenos Aires: Ediciones Culturales Argentinas, 1991. 31-75.

Sterling, Bruce. Mirrorshades: The Cyberpunk Anthology. Nueva York: Arbor House, 1986.

Stephenson, Neal. Cryptonomican. Nueva York: Perennial; Avon, 1999.

Suvin, Darko. Metamorfosis de la ciencia-ficción. México: Fondo de Cultura Económica, 1984.

Volpi, Jorge. "Réquiem por la novela”. La novela según los novelistas. Cristina Rivera Garza, coord. México: Fondo de Cultura Económica, 2007.

Yehya, Naief. El cuerpo transformado. México: Paidós, 2001.

Žižek, Slavoj. “Matriz, o las dos caras de la perversión”. Lacrimae rerum. Ensayos sobre cine moderno y ciberespacio. Buenos Aires: Debate, 2006. 175-206.

$\begin{array}{lllrl}\text { ISSN 0034-9631 (Impreso) } & \text { ISSN 2154-4794 (Electrónico) }\end{array}$ 